\title{
IIIness in childhood predicts face preferences in adulthood
}

Mícheál de Barra ${ }^{1,2,5}$

Lisa M. DeBruine ${ }^{3}$

Benedict C. Jones ${ }^{3}$

Zahid Hayat Mahmud ${ }^{4}$

Valerie A. Curtis ${ }^{1}$

1

Department of Disease Control, London School of Hygiene \& Tropical Medicine

2

Centre for the Study of Cultural Evolution, Stockholm University

3

School of Psychology, University of Aberdeen

${ }^{4}$ International Centre for diarrheal Disease Research, Bangladesh.

5

Corresponding author: mdebarra@gmail.com

Centre for the Study of Cultural Evolution,

Stockholm University,

Stockholm 106 91,

Sweden.

FORTHCOMING IN EVOLUTION AND HUMAN BEHAVIOR 


\title{
IIIness in childhood predicts face preferences in adulthood
}

\begin{abstract}
The value of different mate choices may depend on the local pathogen ecology and on personal infection susceptibility: when there is a high risk of infection, choosing a healthy or immunocompetent mate may be particularly important. Frequency of childhood illness may act as a cue of the ecological and immunological factors relevant to mate preferences. Consistent with this proposal, we found that childhood illness, and frequency of diarrhea in particular, was positively correlated with preferences for exaggerated sex-typical characteristics in opposite-sex, but not same-sex, faces. Moreover, this relationship was stronger among individuals with poorer current health. These data suggest that childhood illness may play a role in calibrating adult mate preferences and have implications for theories of disease- avoidance psychology, life-history strategy and cross-cultural differences in mate preferences.
\end{abstract}

Keywords: facial attractiveness; infectious disease; sexual dimorphism; predictive adaptive response; behavioral immune system. 


\section{Introduction}

Reproductive success is often a function of how well one can mitigate the pervasive costs of infectious disease (Combes, 2001). To this end, humans have evolved a set of immunological and cognitive mechanisms that reduce the impact of infectious agents (Combes, 2001; Curtis et al., 2011; Fumagalli et al., 2011; Schaller \& Park, 2011). The cognitive mechanisms, often referred to as the behavioral immune system (Schaller \& Park, 2011), may also be important in shaping human mate preferences. Mating with healthy partners can (i) reduce the chance that you or future offspring contract an infection from that partner, (ii) lessen the risk that partners' direct investment will be curtailed due to illness, and (iii) increase the likelihood that offspring inherit genes that confer resistance to locally prevalent pathogens (Tybur \& Gangestad, 2011).

Recent work suggests that individual differences in preferences for exaggerated sex-typical characteristics may be a component of the behavioral immune system. Although links between exaggerated sex-typical characteristics and measures of health remain controversial to some researchers (Boothroyd et al., 2005; Scott et al., 2013), recent studies suggest that masculine and testosteronedependent characteristics in men (Gangestad et al., 2010; Rantala et al., 2012; Rhodes et al., 2003; Thornhill \& Gangestad, 2006) and feminine characteristics in women (Gray \& Boothroyd, 2012; Thornhill \& Gangestad, 2006) are positively correlated with measures of actual health (reviewed in Thornhill \& Gangestad, 
2008). Consistent with these findings, masculine men and feminine women are also perceived to be particularly healthy (Johnston et al. 2001; Scott et al. 2008, but see also Boothroyd et al. 2005). Such findings suggest that there may be health-related benefits associated with choosing mates with exaggerated sextypical characteristics. However, given that some research also suggests that people with more exaggerated sex-typical characteristics may be more to infidelity (Hughes \& Gallup, 2003), there may also be costs associated with choosing such individuals as long-term mates. While there is general agreement among researchers that feminine characteristics in women's faces are important for men's mate preferences, evidence that masculine characteristics in men's faces are important for women's mate preferences is considerably more mixed (for review, see Rhodes, 2006). For example, some researchers have found that masculine characteristics have no effect on women's attractiveness ratings of men's faces, at least when faces differ simultaneously on other dimensions (Scott et al., 2010; Stephen et al., 2012), while other studies have reported that masculine characteristics do influence women's judgments of men's attractiveness under these circumstances (Quist et al., 2012; Said \& Todorov, 2011).

While the importance of male masculinity for women's mate choices remains somewhat controversial, there is evidence that disease-related factors can modulate preferences for exaggerated sex-typical characteristics in potential mates in ways that might compensate for actual or perceived vulnerability to 
disease. For example, women who score high on a measure of pathogen disgust (Tybur et al., 2009), which is thought to index individual differences in concerns about disease, show stronger preferences for masculine characteristics in men's faces, voices and bodies (DeBruine et al., 2010b; Jones et al., 2013a). Men scoring higher on pathogen disgust also tend to show stronger preferences for feminine women (Jones et al., 2013b). Additionally, women in geographic regions with higher pathogen loads demonstrate stronger preferences for masculine men (DeBruine et al., 2010a, 2011) and facial cues of high testosterone (Moore et al., 2013). While these correlational findings are open to interpretation because of the potential effects of third variables (Brooks et al., 2011; Little et al., 2011), recent experiments have demonstrated that priming men's and women's concerns about disease directly increased their preferences for exaggerated sextypical characteristics in potential mates, but not in own-sex individuals (Little et al. 2011; see also Lee \& Zietsch 2011; Watkins et al. 2012). A notable criticism of this work is that it has generally investigated individual differences in mate preferences in relatively developed, industrialized countries (Scott et al., 2013). Consequently, tests for converging evidence that disease-related factors predict, and potentially influence, mate preferences in other types of samples would be desirable.

Given children's susceptibility to disease, the local prevalence of childhood infections may be particularly important for mate preferences. Demographic data from Matlab, Bangladesh in 1990 (the site of the current study, and birth year of 
oldest participants) illustrate the severity of children's disease risk: a new-born had a 1 in 9 chance of dying before its fifth birthday while a young adult had a 1 in 165 chance of dying between the ages of 20 and 25 (ICDDRB, 1994).

Data from Matlab also shows that the causes of death are different for adults and children (Adjuik et al., 2006): children were most at risk from diseases like diarrhea and pneumonia while adults were most at risk from TB and other gastrointestinal diseases (ICDDRB, 1994). Together, these findings suggest that an adult's own childhood disease frequency is likely to be a more reliable cue to the disease threat that will be experienced by their offspring than is that adult's current health. Consequently, it is plausible that childhood health will be a particularly important predictor of mate preferences in adulthood; individuals who were in relatively poor health as children may place greater emphasis on the health of potential mates in adulthood, potentially leading to stronger preferences for exaggerated sex-typical characteristics in opposite-sex faces.

Condition-dependent adaptations of this kind are expected to evolve when environmental conditions change at intermediate rates (Penke, 2010). If conditions change rapidly, childhood environment will not be a reliable predictor of the environment decades later when adults reproduce. On the other hand, condition-dependent preferences may be redundant if conditions change very slowly (Penke, 2010). Pathogen stress depends on diverse factors that often display intermediate rates of change, such as where water is sourced, how food is prepared, the nature of intergroup contact, population density, hygiene culture, 
altitude, and weather patterns (Cairncross et al., 1996; Checkley et al., 2000; Kuris, 2012). Thus, responses to disease burden may be condition-dependent. Current health may also predict preferences for exaggerated sex-typical characteristics in opposite-sex faces if, like childhood health, current health is correlated with the prevalence of diseases that threaten offspring health.

A different set of predictions, in which current heath could be negatively correlated with preferences for exaggerated sex-typical characteristics in opposite-sex faces, is suggested by a series of studies that have reported positive correlations between participants' own attractiveness and their mate preferences (reviewed in Little \& Mannion, 2006). Given the positive relationship between attractiveness and health reported in some studies (e.g., Lie et al., 2008), early interpretations of these findings (Little et al., 2001; Penton-Voak et al., 2003) suggested they were examples of condition-dependent preferences (i.e., assortative mating for health), similar to those reported in some other species (see Cotton et al., 2006 for a review). Such findings raise the possibility that childhood and/or current health will be positively, rather than negatively, correlated with preferences for exaggerated sex-typical characteristics in potential mates. However, subsequent research suggests previous findings reporting correlations between own attractiveness and preferences for exaggerated sex-typical characteristics may be better characterized as marketvalue-dependent preferences, rather than condition-dependent preferences (Little \& Mannion, 2006). For example, experimentally increasing women's 
perceptions of their own market value increases their preferences for masculine men (Little \& Mannion, 2006). Further evidence that the effects of own attractiveness on mate preferences may have little to do with one's own health comes from a recent study finding that women's ratings of their own attractiveness were positively correlated with their masculinity preferences, women's ratings of their own health were negatively correlated with their masculinity preferences, and that these correlations were independent (Feinberg et al., 2011). Nonetheless, one previous study has suggested that healthier men and women in rural Malaysia showed stronger preferences for exaggerated sextypical characteristics in potential mates (Scott et al., 2008). In a sample of 25 men and 26 women, this study found that the 13 men and 6 women who reported having never missed work due to illness in the past year had stronger preferences for exaggerated sex-typical characteristics in potential mates than did the 12 men and 20 women who had missed at least one day of work due to illness in the past year.

In light of the above, we investigated the inter-relationships among childhood illness, current illness, and preferences for exaggerated sex-typical facial characteristics in opposite-sex and own-sex faces in a sample of 90 men and 150 women living in rural Bangladesh.

\section{Methods}

Data were collected in Matlab, a rural subdistrict of Bangladesh and the site of a 
long-term health and demographic research program, between September and November 2010. The sample was randomly selected from a list of all individuals born between January 1990 and July 1994 within 16 different villages and included 150 women and 90 men. The mean age at the time of interview was 17.2 years $(S D=1.6$ years $), 86 \%$ were Muslim, $8 \%$ were married, $52 \%$ lived in households with electricity, and $38 \%$ had primary school education only. Participants were interviewed at their homes by one of four experienced fieldworkers.

Childhood health data were extracted from the Matlab Health and Demographic Surveillance System database (HDSS). Research began in Matlab in 1963 as part of a Cholera vaccine trail. In the late 1960s and 1970 the remit of the research in Matlab was broadened and systematic health and demographic data collection began. The data collection is monitored by a field team including research assistants and medical workers, and the HDSS is one of the most detailed high-quality longitudinal databases from the developing world. Community health workers make fortnightly or monthly visits to every household and record births, deaths, migrations, divorce. Data on child health (vaccination, breastfeeding, and disease) are also collected from mothers with children under five. Questions about offspring health were relevant to this study: has the child experienced diarrhea in the past fortnight (defined as "three or more loose stools per 24 hours with or without mucus or blood") or pneumonia in the past month ("symptoms such as fever, cough, rapid breathing, or breathing difficulty and 
chest in-drawing")? These are the two major causes of infant mortality in the region (Baqui et al., 1998). We selected a random sample born between January 1990 and July 1994 because the phrasing and frequency of these two questions remained constant for children born during this period. Recoded diarrhea and pneumonia bouts were summed to form two variables, diarrhea (Mean \pm SD $=$ $6.1 \pm 4.9$ ) and pneumonia (Mean $\pm S D=0.7 \pm 1.4$ ). Diarrhea and pneumonia correlated positively (Spearman's $\rho=.22, p<.01$ ).

We included two socioeconomic status (SES) variables in our analysis. Current SES was calculated using 15 questions on current house size and ownership of household goods (e.g. TV, mobile phone). Childhood SES was created using data on dwelling size, land ownership, and household possessions from the 1996 census (Rahman et al., 2001). Both variables were calculated using principal component analysis: for each set, all questions loaded on a single factor, representing wealth. Component scores formed the weights in a regression equation used to calculate a household SES score. Missing childhood SES data from 49 participants was replaced using an expectation maximization procedure (Moon, 1996); scores were derived from the variables current SES, household cleanliness, and participant education level. Childhood and current SES scores were uncorrelated $(r=-.06, p=.4)$. Education level was associated with current SES (Spearman's $\rho=.4, p<.001$ ) but not with childhood SES (Spearman's $\rho=$ $.08, p=.3)$. Education level was measured a five-point scale: none $(5 \%$ of participants), primary $(37.9 \%)$, secondary $(44.2 \%)$, higher secondary $(12.5 \%)$, 
and tertiary $(0.4 \%)$.

Any relationship between health and face preferences may be confounded by the effects of an unhygienic environment on both these variables (Curtis et al., 2003). Fieldworkers therefore answered eight binary questions about household and participant cleanliness. These were summed to create a cleanliness variable, with higher scores indicating a cleaner environment. Cleanliness was not correlated with current SES (Spearman's $\rho=.03, p=.6$ ).

To create the face stimuli we took full-color digital face images of 15 Bangladeshi men and 15 Bangladeshi women. Masculinized versions of each face were created by adding $50 \%$ of the vector differences in $2 \mathrm{D}$ shape between a symmetrized male prototype with the average shape of the 15 male faces and a symmetrized female prototype with the average shape of the 15 female faces to each individual face. Feminized versions of each face were manufactured by subtracting $50 \%$ of these same shape differences from each individual face. This process created 15 pairs of male face images and 15 pairs of female face images, each pair consisting of a masculinized and feminized version of the same individual. This process has been used to construct face stimuli in many papers and alters perceptions of masculinity-femininity in the predicted manner (e.g. DeBruine et al. 2006; Jones et al. 2010; Perrett et al. 1998).

A masculinized and feminized version of each face was printed in high resolution 
on A4 sheets of photopaper (left/right position randomized). During the interview, participants were presented with the face pairs in a random order and asked to point at the one they thought was most attractive. Some participants were accidentally not shown all sheets; however $76 \%$ saw all 30 sheets and $97 \%$ saw 28 or more. The face preference variable represents the percentage of the sheets (i.e., trials) in which masculinized male faces were chosen over feminized male faces and in which feminized female faces were chosen over masculinized female faces.

Participants were also asked if they had experienced 14 different infectious diseases over the past 12 months; positive responses were summed to form a recent illness variable. This health questionnaire was adapted from the 1996 health and demography survey (Rahman et al., 2001). The most commonly reported infections were influenza (66.3\% of participants), gastric pain or ulcer (32.1\%), cough $(27.9 \%)$, vomiting $(23.8 \%)$, diarrhea $(22.5 \%)$, and toothache (12.1\%). Together these accounted for $80 \%$ of illness making up the recent illness variable. Recent illness and childhood diarrhea correlated (Spearman's $\rho$ $=.14, p=.03$ ) but here was no association between childhood pneumonia and recent illness (Spearman's $\rho=.06, p=.38$ ).

Ethical clearance for this study was granted by the London School of Hygiene and Tropical Medicine and the International Centre for Diarrheal Disease Research, Bangladesh. The general aims and methods of the study were 
explained to each participant and written consent was obtained before beginning the experiment.

\section{Results}

When asked to pick the more attractive face, women were more likely to pick the feminized female faces (one sample t-test, Mean \pm SE $=58.04 \% \pm 1.22, t_{149}=$ $6.58, p<.001, d=0.54)$ and feminized male faces (Mean $\pm S E=44.02 \% \pm 1.30$, $\left.\mathrm{t}_{149}=-4.58, \mathrm{p}<.001, \mathrm{~d}=0.37\right)$ than the masculinized versions. Men were more likely to choose the masculinized versions of male faces (one sample t-test, Mean \pm SE $=53.44 \% \pm 1.62, t_{89}=2.13, p=.04, d=.22$ ) but showed no clear preferences with regard to female faces (Mean $\pm S E=50.92 \% \pm 1.61, t_{89}=0.56, p$ $=.58, \mathrm{~d}=.06)$. Compared to the men, women showed stronger preferences for femininity in both female (two sample t-test, $\mathrm{t}_{238}=3.49, \mathrm{p}<.001, \mathrm{~d}=0.46$ ) and male faces $\left(\mathrm{t}_{238}=4.49, \mathrm{p}<.001, \mathrm{~d}=0.60\right)$. 
Table 1: Preference for dimorphism in same-sex and opposite-sex faces

\begin{tabular}{|c|c|c|c|c|c|c|}
\hline & \multicolumn{3}{|c|}{ Univariate } & \multicolumn{3}{|c|}{ Multivariate } \\
\hline & $\mathrm{B}$ & $95 \% \mathrm{CI}$ & $\beta$ & $\mathrm{B}$ & $95 \% \mathrm{CI}$ & $\beta$ \\
\hline \multicolumn{7}{|c|}{ Preference for exaggerated sex-typical shape characteristics in opposite-sex faces } \\
\hline Childhood diarrhea & 0.68 & {$[0.27,1.10]$} & $0.20 * *$ & 0.64 & {$[0.24,1.05]$} & $0.19 * *$ \\
\hline Childhood pneumonia & -1.10 & {$[-2.61,0.40]$} & -0.09 & & & \\
\hline Recent illness & 0.57 & {$[-0.60,1.74]$} & 0.06 & & & \\
\hline Current SES & 1.73 & {$[-0.28,3.74]$} & 0.11 & & & \\
\hline Childhood SES & 1.28 & {$[-1.17,3.73]$} & 0.07 & & & \\
\hline Cleanliness & -0.41 & {$[-2.38,1.56]$} & -0.03 & & & \\
\hline Education level & 0.17 & {$[-2.50,2.83]$} & 0.01 & & & \\
\hline Age & 1.18 & {$[-0.08,2.43]$} & 0.12 & & & \\
\hline Sex & 6.90 & {$[2.72,11.08]$} & $0.21 * *$ & 6.53 & {$[2.42,10.64]$} & $0.20 * *$ \\
\hline \multicolumn{7}{|c|}{ Preference for exaggerated sex-typical shape characteristics in same-sex faces } \\
\hline Childhood diarrhea & -0.28 & {$[-0.68,0.12]$} & -0.09 & & & \\
\hline Childhood pneumonia & -0.18 & {$[-1.59,1.24]$} & -0.02 & & & \\
\hline Recent illness & -0.26 & {$[-1.36,0.84]$} & -0.03 & & & \\
\hline Current SES & -1.35 & {$[-3.24,0.54]$} & -0.09 & & & \\
\hline Childhood SES & 0.96 & {$[-1.21,3.14]$} & 0.06 & & & \\
\hline Cleanliness & 0.97 & {$[-0.89,2.83]$} & 0.07 & & & \\
\hline Education level & 0.87 & {$[-1.63,3.37]$} & 0.04 & & & \\
\hline Age & -0.49 & {$[-1.68,0.69]$} & -0.05 & & & \\
\hline Sex & -4.60 & {$[-8.56,-0.63]$} & $-0.15^{*}$ & & & \\
\hline
\end{tabular}

Note: $B$ is the coefficient value; $\beta$ is the standardized coefficient value; ${ }^{*} p<.05$; ${ }^{* *} p<.01$.

Simple linear regressions showed that childhood diarrhea was positively correlated with preference for exaggerated sex-typical characteristics in oppositesex, but not same-sex, faces (see Table 1). Participant sex predicted preferences for exaggerated sex-typical characteristics in both opposite-sex and same-sex faces (see Table 1). No other variables showed significant effects. Multivariate analyses showed that the effect of childhood diarrhea on judgments of oppositesex faces remained significant when controlling for the effects of participant sex (see Table 1). Alternative analyses using Probit regression showed the same pattern of results. 


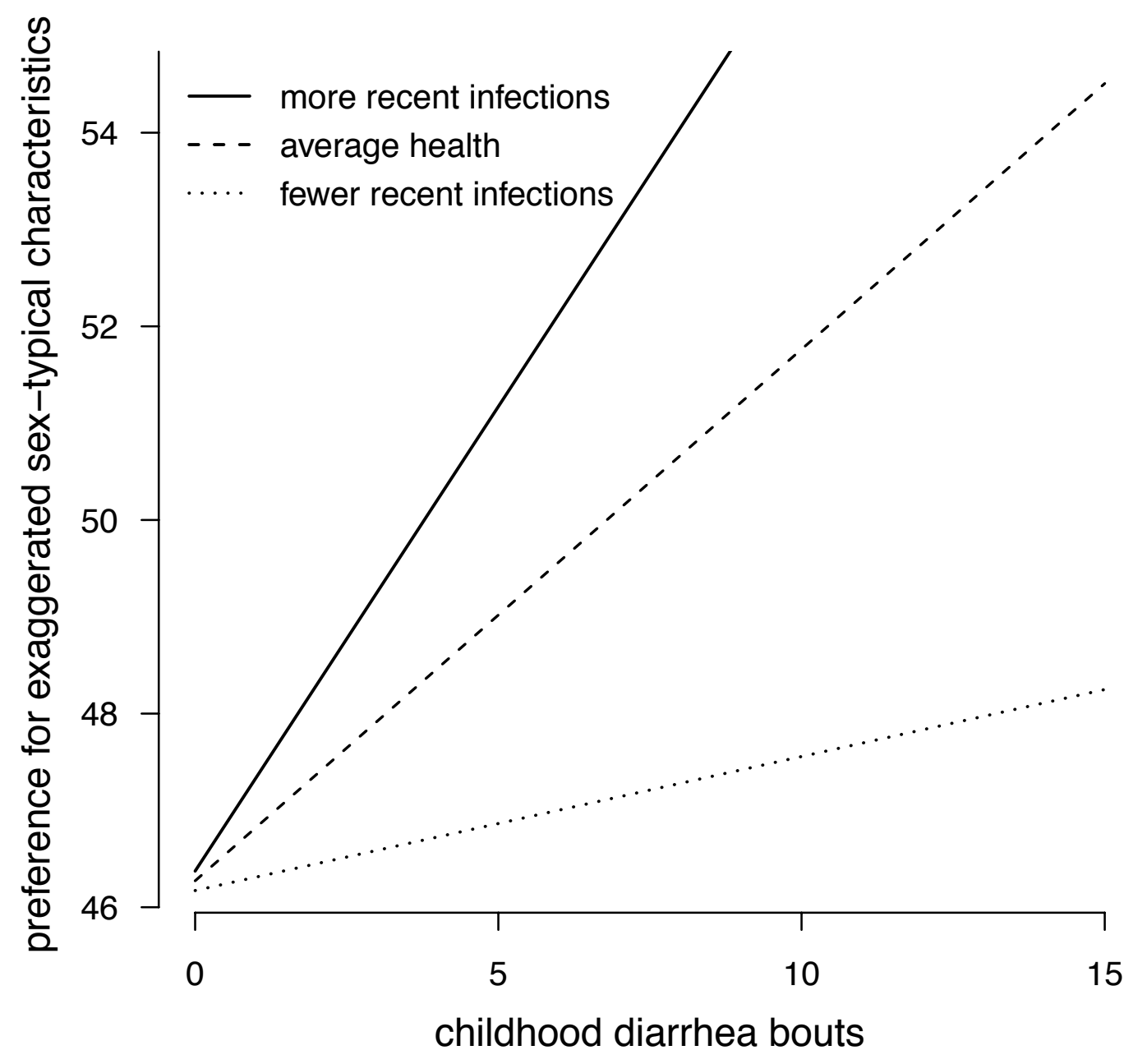

Figure 1: The relationship between diarrhea in childhood and preference for sexually dimorphic faces depends on health over the past year. Lines represent people with 1 SD more infections, people with average number of infections, and people with $1 \mathrm{SD}$ fewer infections. Independent variables were centered by subtracting the mean from each value.

A post-hoc multiple linear regression revealed a significant interaction between childhood diarrhea and recent illness for judgments of opposite-sex faces (predictors: recent illness, childhood diarrhea, and the interaction term, $B=0.26$, $95 \% \mathrm{Cl}=[0.04,0.47], \beta=0.15, p=.022)$. Figure 1 illustrates this interaction 
and shows that the relationship between childhood diarrhea and preferences for exaggerated sex-typical features in opposite-sex faces was stronger among participants who had experienced poorer health over the past year.

\section{Discussion}

We found that men and women who were more frequently ill with diarrhea as children showed stronger preferences for exaggerated sex-typical shape characteristics in opposite-sex, but not own-sex, faces. These findings linking childhood illness to mate preferences in adulthood complement other recent studies reporting correlations between disease-related factors and mate preferences (DeBruine et al., 2010a, 2011, 2012; Jones et al., 2013a, 2013b; Lee \& Zietsch, 2011; Little et al., 2011; Moore et al., 2013). While these latter findings focused on mate preferences in developed, industrialized societies, our findings for mate preferences in the Matlab region of rural Bangladesh suggest that disease-related factors may play a similar role in the mate preferences of individuals in low-income, agricultural societies. This is potentially noteworthy, since it suggests that disease may be important for mate preferences across a relatively wide range of ecological conditions.

By contrast with our findings for childhood illness, current health did not directly predict face preferences. However, we did observe an interaction between childhood and current illness, whereby the effect of childhood illness was greater in individuals currently in poor health. This interaction may occur if offspring 
health is particularly important for the reproductive success of individuals whose current health compromises the investment they are able to provide their offspring. Together, these results support our prediction that childhood illness may play an important role in shaping mate preferences in adulthood because an adult's own childhood disease frequency is likely to be a more reliable cue to the disease threat that will be experienced by their offspring than is that adult's current health. Previous research suggests that individuals who perceive themselves to have higher market value show stronger preferences for potential mates displaying exaggerated sex-typical characteristics (see, e.g., Feinberg et al., 2011 and Little \& Mannion, 2006). That healthier individuals tended to show weaker, rather than stronger, preferences for potential mates displaying exaggerated sex-typical characteristics in the current study is then consistent with the possibility that health-related factors and market value can have dissociable effects on mate preferences (see, e.g., Feinberg et al., 2011 and Little \& Mannion, 2006).

While we found that childhood diarrhea predicted mate preferences in adulthood, childhood pneumonia did not. There are several possible reasons for this null result. Only diarrhea predicted current health, suggesting that diarrhea is a more reliable predictor of general long-term health than pneumonia. This is perhaps unsurprising; childhood diarrhea is associated with poor sanitation and hygiene (Prüss et al., 2002) and rates may therefore covary with exposure to a broader range of diseases (e.g., soil transmitted helminths) than a directly transmitted 
disease like pneumonia. Alternatively, diarrhea incidence may have been measured with greater accuracy than pneumonia, perhaps because pneumonia is less common disease ( 0.7 bouts per child compared with 6.1 bouts of diarrhea in this sample, see also, e.g., Brooks et al., 2005) or because some symptoms overlap with other ailments including non-infectious diseases like asthma. In addition, the rarity of pneumonia may have limited our statistical power to detect an effect of the disease.

Given that this study investigated natural variation in childhood health (rather than experimentally manipulating disease exposure), it is possible that the association between health and face preferences is driven by correlates of childhood illness. While we controlled for several potential confounds in our analyses (current SES, childhood SES, cleanliness, education level, and age), this list is obviously not exhaustive. Consequently, we emphasize here that the effects of other potential confounds (e.g., own mate value) will need to be excluded before strong claims about the causal nature of childhood illness on adult mate preferences can be made.

Although we found little evidence that current illness directly predicted mate preferences, a previous study in a smaller, rural Malaysian sample previously found that individuals who reported having never missed work due to illness in the past year had stronger preferences for exaggerated sex-typical characteristics in potential mates than did individuals who had missed at least 
one day of work due to illness in the past year (Scott et al., 2008). Why these results differ from ours is unclear, though possibilities include differences in the type of health data analyzed and characteristics of the samples. It is possible that the relationship between health and mate preferences can be modulated by other aspects of ecological conditions that were not considered in either our study or others'. Indeed, men in rural Bangladesh did not show general preferences for feminine women. Consistent with this result, Penton-Voak et al. (2004) found that men in rural Jamaican, another harsh environment, showed no strong preference for feminine women. These results raise the possibility that aspects of environmental harshness that are unrelated to infectious disease also shape mate preferences.

Previous work exploring the mechanisms through which disease-related factors come to predict mate preferences have focused on the effects of recent experience of potential disease cues (Lee \& Zietsch, 2011; Little et al., 2011). Here we present new evidence suggesting that experience of illness during development may also play an important role in shaping mate preferences in adulthood, potentially because people use childhood experience of illness to gauge child-specific aspects of local pathogen stress. These results resonate with other recent research suggesting that childhood stability and health calibrate the timing of other life history events such as age at first child's birth (Nettle et al., 2011; Waynforth, 2012). Moreover, our data suggest that the effects of childhood illness can be modulated by current health, underlining the complexity of the 
processes through which disease may shape mate preferences in adulthood. Further research is needed to clarify the mechanisms through which the relationship between childhood illness and adult mate preference emerges. Our findings suggest that this research will prove to be a fruitful line of inquiry.

\section{References}

Adjuik, M., Smith, T., Clark, S., Todd, J., Garrib, A., Kinfu, Y., Kahn, K., Mola, M., Ashraf, A., Masanja, H., Adazu, K., Adazu, U., Sacarlal, J., Alam, N., Marra, A., Gbangou, A., Mwageni, E., \& Binka, F. (2006). Cause-specific mortality rates in sub-Saharan Africa and Bangladesh. Bulletin of the World Health Organization, 84, 181-188.

Baqui, A. H., Black, R. E., Arifeen, S. E., Hill, K., Mitra, S. N., \& al Sabir, A. (1998). Causes of childhood deaths in Bangladesh: results of a nationwide verbal autopsy study. Bulletin of the World Health Organization, 76, 161171.

Boothroyd, L. G., Burt, D. M., Cornwell, R. E., Jones, B. C., Little, A. C., Tiddeman, B. P., \& Perrett, D. I. (2005). Facial masculinity is related to perceived age but not perceived health. Evolution and Human Behavior, $26,417-431$.

Brooks, W. A., Santosham, M., Naheed, A., Goswami, D., Wahed, M. A., DienerWest, M., Faruque, A. S. G., \& Black, R. E. (2005). Effect of weekly zinc supplements on incidence of pneumonia and diarrhoea in children younger than 2 years in an urban, low-income population in Bangladesh: 
randomised controlled trial. The Lancet, 366(9490), 999-1004

Brooks, R., Scott, I. M., Maklakov, A. A., Kasumovic, M. M., Clark, A. P., \& Penton-Voak, I. S. (2011). National income inequality predicts women's preferences for masculinised faces better than health does. Proceedings of the Royal Society B, 278, 810-812.

Cairncross, S., Blumenthal, U., Kolsky, P., Moraes, L., \& Tayeh, A. (1996). The public and domestic domains in the transmission of disease. Tropical Medicine \& International Health, 1(1), 27-34.

Checkley, W., Epstein, L. D., Gilman, R. H., Figueroa, D., Cama, R. I., Patz, J. A., \& Black, R. E. (2000). Effects of El Niño and ambient temperature on hospital admissions for diarrhoeal diseases in Peruvian children. The Lancet, 355(9202), 442-450.

Combes, C. (2001). Parasitism: The Ecology and Evolution of Intimate Interactions. University of Chicago Press, Chicago.

Cotton, S., Small, J. \& Pomiankowski, A. (2006). Sexual selection and conditiondependent mate preferences. Current Biology, 16, R755-R765.

Curtis, V. A., de Barra, M., \& Aunger, R. (2011). Disgust as an adaptive system for disease avoidance behaviour. Philosophical Transactions of the Royal Society B, 366, 389-401.

DeBruine, L. M., Jones, B. C., Crawford, J. R., Welling, L. L. M., \& Little, A. C. (2010a). The health of a nation predicts their mate preferences: crosscultural variation in women's preferences for masculinized male faces. Proceedings of the Royal Society B, 277, 2405-2410. 
DeBruine, L. M., Jones, B. C., Little, A. C., Boothroyd, L. G., Perrett, D. I., Penton-Voak, I. S., Cooper, P. A., Penke, L., Feinberg, D. R., \& Tiddeman, B. P. (2006). Correlated preferences for facial masculinity and ideal or actual partner's masculinity. Proceedings of the Royal Society B, $273,1355-1360$.

DeBruine, L. M., Jones, B. C., Little, A. C., Crawford, J. R., \& Welling, L. L. M. (2011). Further evidence for regional variation in women's masculinity preferences. Proceedings of the Royal Society B, 278, 813-814.

DeBruine, L. M., Jones, B. C., Tybur, J. M., Lieberman, D., \& Griskevicius, V. (2010b). Women's preferences for masculinity in male faces are predicted by pathogen disgust, but not by moral or sexual disgust. Evolution and Human Behavior, 31, 69-74.

DeBruine, L. M., Little, A. C., \& Jones, B. C. (2012). Extending parasite-stress theory to variation in human mate preferences. Behavioral and Brain Sciences, 35, 86-87.

Feinberg, D. R., DeBruine, L. M., Jones, B. C., Little, A. C., O'Connor, J. J. M., \& Tigue, C. C. (2011). Women's self-perceived health and attractiveness predict their male vocal masculinity preferences in different directions across short- and long-term relationship contexts. Behavioral Ecology and Sociobiology, 66, 413-418.

Fumagalli, M., Sironi, M., Pozzoli, U., Ferrer-Admettla, A., Pattini, L., and Nielsen, R. (2011). Signatures of environmental genetic adaptation pinpoint pathogens as the main selective pressure through human 
evolution. PLoS Genetics, 7, e1002355.

Gangestad, S. W., Merriman, L. A., \& Emery Thompson, M. (2010). Men's oxidative stress, fluctuating asymmetry and physical attractiveness. Animal Behaviour, 80, 1005-1013.

Gray, A. W. \& Boothroyd, L. G. (2012). Female facial appearance and health. Evolutionary Psychology, 10, 66-77.

Hughes, S. M., \& Gallup Jr, G. G. (2003). Sex differences in morphological predictors of sexual behavior: Shoulder to hip and waist to hip ratios. Evolution and Human Behavior, 24, 173-178.

ICDDRB (1994). Dempgraphic Survillance System - Matlab: Registration of Demographic Events - 1990.

Johnston, V. S., Hagel, R., Franklin, M., Fink, B., and Grammer, K. (2001). Male facial attractiveness: evidence for a hormone-mediated adaptive design. Evolution and Human Behavior, 22, 251-267.

Jones, B. C., Feinberg, D. R., Watkins, C. D., Fincher, C. L., Little, A. C., and DeBruine, L. M. (2013a). Pathogen disgust predicts women's preferences for masculinity in men's voices, faces, and bodies. Behavioral Ecology, 4(2), 373-379.

Jones, B. C., Fincher, C. L., Welling, L. L. M., Little, A. C., Feinberg, D. R., Watkins, C. D., Al-Dujaili, E. A. S. \& DeBruine, L. M. (2013b). Salivary cortisol and pathogen disgust predict men's preferences for feminine shape cues in women's faces. Biological Psychology, 92, 233-240.

Jones, B. C., Main, J. C., DeBruine, L. M., Little, A. C., \& Welling, L. L. M. (2010). 
Reading the look of love. Sexually dimorphic cues in opposite-sex faces influence gaze categorization. Psychological Science, 21, 796-798.

Lee, A. J. \& Zietsch, B. P. (2011). Experimental evidence that women's mate preferences are directly influenced by cues of pathogen prevalence and resource scarcity. Biology Letters, 7, 892-895.

Lie, H. C., Rhodes, G., \& Simmons, L. W. (2008). Genetic diversity revealed in human faces. Evolution, 10, 2473-2486.

Little, A. C., Burt, D. M., Penton-Voak, I. S., \& Perrett, D. I. (2001). Selfperceived attractiveness influences human female preferences for sexual dimorphism and symmetry in male faces. Proceedings of the Royal Society $B, 268,39-44$.

Little, A. C., DeBruine, L. M., \& Jones, B. C. (2011). Exposure to visual cues of pathogen contagion changes preferences for masculinity and symmetry in opposite-sex faces. Proceedings of the Royal Society B, 278, 2032- 2039.

Little, A. C. and Mannion, H. (2006). Viewing attractive or unattractive same-sex individuals changes self-rated attractiveness and face preferences in women. Animal Behaviour, 72, 981-987.

Moon, T. (1996). The expectation-maximization algorithm. IEEE Signal Processing Magazine, 13, 47-60.

Moore, F. R., Coetzee, V., Contreras-Garduño, J., DeBruine, L. M., Kleisner, K., Krams, I., Marcinkowska, U., Nord, A., Perrett, D. I., Rantala, M. J., Schaum, N. \& Suzuki, T. N. (2013). Cross-cultural variation in women's preferences for cues to sex- and stress-hormones in the male face. 
Biology Letters, 9(50). doi:10.1098/rsbl.2013.0050

Nettle, D., Coall, D. A., \& Dickins, T. E. (2011). Early-life conditions and age at first pregnancy in British women. Proceedings of the Royal Society B, 278, $1721-1727$.

Penton-Voak, I. S., Jacobson, A., \& Trivers, R. (2004). Populational differences in attractiveness judgements of male and female faces. Evolution and Human Behavior, 25, 355-370.

Penton-Voak, I. S., Little, A. C., Jones, B. C., Burt, D. M., Tiddeman, B. P., \& Perrett, D. I. (2003). Female condition influences preferences for sexual dimorphism in faces of male humans (Homo sapiens). Journal of Comparative Psychology, 117, 264-271.

Perrett, D. I., Lee, K. J., Penton-Voak, I. S., Rowland, D., Yoshikawa, S., Burt, D. M., Henzi, S. P., Castles, D. L., \& Akamatsu, S. (1998). Effects of sexual dimorphism on facial attractiveness. Nature, 394, 884-887.

Prüss, A., Kay, D., Fewtrell, L., \& Bartram, J. (2002). Estimating the burden of disease from water, sanitation, and hygiene at a global level. Environmental Health Perspectives, 110, 537-542.

Quist, M., DeBruine, L. M., Little, A. C., \& Jones, B. C. (2012). Integrating social knowledge and physical cues when judging the attractiveness of potential mates. Journal of Experimental Social Psychology, 48, 770-773.

Rahman, O., Menken, J., Foster, A., \& Gertler, P. (2001). Matlab (Bangladesh) health and socioeconomic survey (MHSS) 1996. Technical report, RAND, Santa Monica, CA. 
Rantala, M. J., Moore, F. R., Skrinda, I., Krama, T., Kivleniece, I., Kecko, S., \& Krams, I. (2012). Evidence for the stress-linked immunocompetence handicap hypothesis in humans. Nature Communications, 3, 694.

Rhodes, G. (2006). The evolutionary psychology of facial beauty. Annual Review of Psychology, 57, 199-226.

Rhodes, G., Chan, J., Zebrowitz, L. A., \& Simmons, L. W. (2003). Does sexual dimorphism in human faces signal health? Proceedings of the Royal Society $B, 270$, S93-95.

Said, C. P. \& Todorov, A. (2011). A statistical model of facial attractiveness. Psychological Science, 22, 1183-1190.

Schaller, M. and Park, J. H. (2011). The Behavioral Immune System (and Why It Matters). Current Directions in Psychological Science, 20, 99-103.

Scott, I., Swami, V., Josephson, S. C., \& Penton-Voak, I. S. (2008). Contextdependent preferences for facial dimorphism in a rural Malaysian population. Evolution and Human Behavior, 29, 289-296.

Scott, I. M. L., Clark, A. P., Boothroyd, L. G., \& Penton-Voak, I. S. (2013). Do men's faces really signal heritable immunocompetence? Behavioral Ecology, 24(3), 579-589.

Scott, I. M. L., Pound, N., Stephen, I. D., Clark, A. P., \& Penton-Voak, I. S. (2010). Does Masculinity Matter? The Contribution of Masculine Face Shape to Male Attractiveness in Humans. PLoS ONE, 5, e13585.

Stephen, I. D., Scott, I. M. L., Coetzee, V., Pound, N., Perrett, D. I., \& PentonVoak, I. S. (2012). Cross-cultural effects of color, but not morphological 
masculinity, on perceived attractiveness of men's faces. Evolution and Human Behavior, 33, 260-267.

Thornhill, R. \& Gangestad, S. W. (2006). Facial sexual dimorphism, developmental stability, and susceptibility to disease in men and women. Evolution and Human Behavior, 27, 131-144.

Thornhill, R. \& Gangestad, S. W. (2008). The Evolutionary Biology of Human Female Sexuality. Oxford University Press, Oxford, UK.

Tybur, J. M. \& Gangestad, S. W. (2011). Mate preferences and infectious disease: theoretical considerations and evidence in humans. Philosophical Transactions of the Royal Society B, 366, 3375-3388.

Tybur, J. M., Lieberman, D., \& Griskevicius, V. (2009). Microbes, mating, and morality: individual differences in three functional domains of disgust. Journal of Personality and Social Psychology, 97, 103-122.

Watkins, C. D., DeBruine, L. M., Little, A. C., Feinberg, D. R., \& Jones, B. C. (2012). Priming concerns about pathogen threat versus resource scarcity: Dissociable effects on women's perceptions of men's attractiveness and dominance. Behavioral Ecology and Sociobiology, 66(12), 1549-1556.

Waynforth, D. (2012). Life-history theory, chronic childhood illness and the timing of first reproduction in a British birth cohort. Proceedings of the Royal Society B, 279(1740), 2998-3002. 